Diabetologia $9,115-119(1973)$

(C) by Springer-Verlag 1973

\title{
Ultrastructural Morphometry of the Pancreatic $\beta$-Cell
}

\author{
P.M. Dean \\ Department of Pharmacology, University of Cambridge, Medical School, Hills Road, Cambridge, England
}

Received: August 3, 1972, accepted: December 11, 1972

Summary. Standard stereological methods have been used to determine the morphometric parameters of organelles contained in the $\beta$-cells of mouse pancreas. Sectioned material from ten islets was analysed at three levels of magnification in the electron microscope. Quantitative data was obtained about the volume number and surface area of the various cytological components and was expressed as density per $\mathbf{c m}^{3}$ of tissue and as absolute dimensions for the average $\beta$-cell. The organelles studied were the nucleus, cytoplasmic ground substance, rough and smooth endoplasmic reticulum, the ribosomes, mitochondria, $\beta$-granules and microtubules.

Key words: Mouse $\beta$-cell, ultrastructure, stereology, morphometry, electron microscopy.

\section{Introduction}

In order to produce a model for the secretion of insulin from pancreatic $\beta$-cells it is essential to have quantitative information about the ultrastructure of the cells. This type of data would enable correlations to be made between biochemical, biophysical and ultrastructural changes occurring during the secretory process. Standard stereological methods are available for reliable measurements to be made of the spatial characteristics of cell organelles by simple counting and measuring procedures applied to electron micrographs of sectioned tissues (Elias, Hennig and Schwartz, 1971). In this study unstimulated cells from the islets of Langerhans of mouse pancreas have been selected for stereological analysis because mouse islets have proved of particular value in elucidating the biochemical (Hellman, 1970) and biophysical (Dean and Matthews, $1970 \mathrm{a}, \mathrm{b})$ changes associated with the secretion of insulin from the $\beta$-cell.

\section{Methods}

Albino mice of either sex previously fed ad libitum, weighing between $30-40 \mathrm{~g}$, were sacrificed by decapitation. The pancreas was rapidly removed and placed in a Krebs Henseleit solution containing glucose $2.8 \mathrm{mM}$ at $37^{\circ} \mathrm{C}$ gassed with $95 \% \mathrm{O}_{2}$ and $5 \% \mathrm{CO}_{2}$ (Dean and Matthows, 1970a). Islets of Langerhans were micro-dissected from the pancreatic tissue, incubated for $60 \mathrm{~min}$ in Krebs Henseleit solution, and subsequently fixed in $2 \%$ glutaraldehyde buffered with sodium phosphate $0.15 \mathrm{M}$ at pH 7.4 for $18 \mathrm{~h}$; they were then post fixed with osmic acid $1 \%$ for $2 \mathrm{~h}$. The tissue was dehydrated in alcohol, embedded in epon resin and sectioned with a diamond knife on an L.K.B. ultramicrotome; the sections were about $750 \AA$ thick. The sections were placed on 200 mesh copper grids, stained with uranyl acetate and lead citrate, and examined in a Phillips EM 300 electron microscope. Ten islets were used, each from a different mouse pancreas.

Seven sections were taken at $7 \mu$ intervals from each tissue block. Electron micrographs were taken from the 70 sections and printed with a final magnification of 10846,34850 and 85340 . Random sampling of the micro- scopic field was achieved by using a specified corner of the copper grid as a reference system for each micrograph (Weibel, Kistler and Scherle, 1966). One photograph at each magnification was taken for every section.

\section{Morphometric analysis of micrographs}

Standard stereological procedures were used to estimate the volume, surface area and number of $\beta$-cells and their organelles in a specified volume of tissue. These methods have been reviewed by Flias (1967); Weibel (1969); and Elias, Hennig and Schwartz (1971).

Point counting was used to calculate the volume occupied by an organelle per unit volume of tissue (volumetric density $V_{V i}$ ) by placing a lattice of $P_{T}$ test points on a micrograph and obtaining the fraction $P_{P i}=P i / P_{T}$ of these points enclosed within the profiles of these organelles $V_{V i}=P_{P i} \quad$ equation 1 .

The surface area of a structure per unit volume of tissue $\left(S_{V i}\right)$, was derived from counting the number of intersection points $(I i)$ of the surface profile with test lines of known total length, $L_{T}$

$$
S_{V i}=2 I i / L_{T} \quad \text { Equation } 2 .
$$

The number of mitochondria per unit volume of tissue $\left(N_{V i}\right)$ was estimated from counts of mitochondrial profiles in a test area of known size.

$$
N_{V i}=\frac{K}{\beta_{i}} \times \frac{N_{A i} 3 / 2}{V_{V i} 1 / 2} \quad \text { Equation } 3 .
$$

where $N_{A i}$ is the number of profiles per unit test area. The shape coefficient $\beta$ was dependent on the axial ratio of the mitochondria on the assumption that mitochondria are cylindrical structures, $\beta$ had a value of 2.0 (Weibel, 1969). $K$ is a stereological coefficient and is dependent on the coefficient of variation of profile length. For a coefficient of variation in mitochondrial size of $18 \%, K$ has a value of 1.1 (Weibel, 1969).

The diameter of $\beta$-granules was calculated by meas. uring the profile diameters with a Standardgraph circular stencil and, using the Wicksell transformation equations to convert the distribution of apparent profile diameters into the distribution of real granule diameters, the mean granule diameter D was obtained (Wicksell, 1925). 'The number of $\beta$-granules per unit volume of tissue was calculated from the relationship (De Hoff and Rhines, 1961);

$$
N_{V i}=N_{A i} / D \quad \text { Equation } 4 .
$$

The morphometric grids used were a coherent quadratic lattice, 340 points for volume and number measure- 
ments, and a coherent 330 line lattice for surface measurements. (Fig. 1). In Table 1 are shown the morphometric parameters measured at each electron micrograph magnification. shape. If the cell were a cube, side length could be estimated from the volume or surface area of the cell, yielding side lengths of $11.3 \mu$ and $12.7 \mu$ respectively.

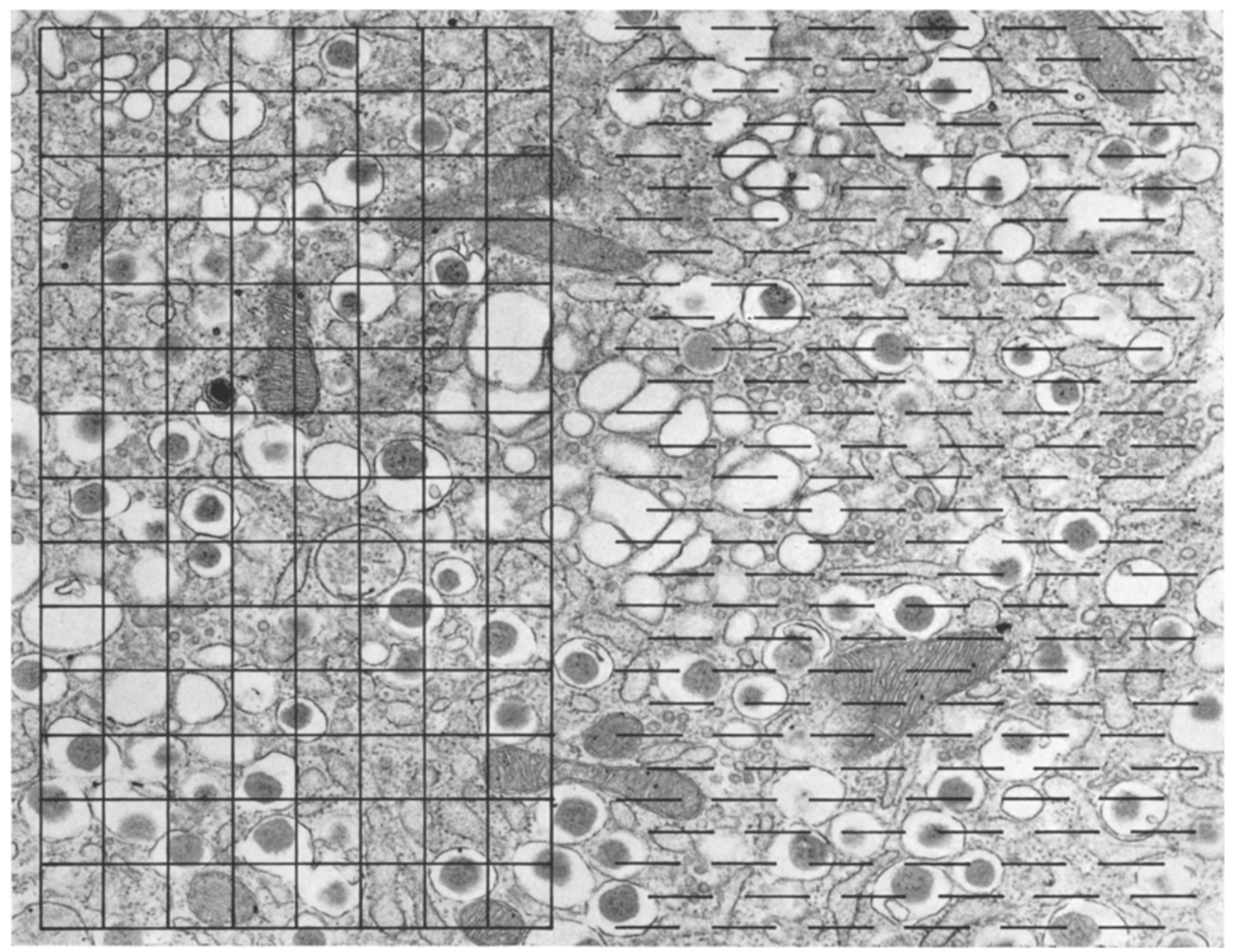

Fig. 1. Electron micrograph of an islet $\beta$-cell with a coherent quadratic lattice and a coherent line lattice superimposed. Line length $=0.286 \mu$

\section{Results}

The morphometric parameters for the ultrastructure of islet $\beta$-cells are expressed in Table 2 . $\beta$-cells comprised $88 \%$ of the volume of a single islet of Langerhans, no further subdivision of extra $\beta$-cellular space was attempted. Cell volume was calculated from the mean area enclosed within cell membrane profiles using equation 1 and found to give a mean value of $1434 \mu^{3}$. Using this value for cell volume the number of cells present in $1 \mathrm{~cm}^{3}$ of islet tissue was estimated at $618 \times 10^{6}$. The surface area of $\beta$-cells in a $1 \mathrm{~cm}^{3}$ volume of islet tissue was calculated by counting the fraction of test lines intersected by the membrane profile and using this value in equation 2. The result was $0.6 \mathrm{M}^{2}$, corresponding to a surface area for one $\beta$-cell of $973 \mu^{2}$. In section the profiles of $\beta$-cells were angular suggesting a polyhedral structure for cell
The $\beta$-cells were subdivided into the following volumetric compartments, the nucleus, the cytoplasm, the cisternae of the rough and smooth endoplasmic reticulum, mitochondria, $\beta$-granules and cytoplasmic ground substance.

Of the 342 cell profiles examined, no cell profile had more than one nuclear profile contained within it, therefore it has been assumed that $\beta$-cells are mononuclear. The volume of nuclear material was found to be $0.104 \mathrm{~cm}^{3} / \mathrm{cm}^{3}$, one nucleus having a volume of $168 \mu^{3}$ and occupying $11.7 \%$ of cell volume. By subtraction the volume of cell cytoplasm is $1266 \mu^{3}$.

Approximately $20 \%$ of cell volume was enclosed by the cisternae of the endoplasmic reticulum, about ${ }_{2}^{2}{ }_{3} \mathrm{rds}$ of which are in the rough form, i.e. $191 \mu^{3}$. The surface density for cisternal membranes in cytoplasm was $32.2 \mu^{2} / \mu^{3}$ for rough and $26.5 \mu^{2} / \mu^{3}$ for smooth endoplasmic reticulum. Smooth endoplasmic 
reticulum including the Golgi apparatus occupied a cell volume of $89 \mu^{3}$ having a surface area of $2359 \mu^{2}$. Rough endoplasmic reticulum had a surface area of $6158 \mu^{2}$ and was studded with ribosomes. The number of ribosomes attached to $1 \mu^{2}$ of rough endoplasmic reticulum was calculated to be 218 , corrected for ribosomal diameter and section thickness according to the method of Haug (1967). A cell, therefore, contained 1.34 million ribosomes on the surface of the rough endoplasmic reticulum. mitochondrion were calculated on this basis to be $0.0509 \mu^{3}$ and $0.818 \mu^{2}$. These values agree closely with those calculated from the morphometric equations.

In a slice taken through a cell, the diameters of the $\beta$-granule profiles are not the true diameters of the granules, the measured profile diameter is in fact an apparent diameter. Wicksell (1925) presented a method for finding the size distribution of the true diameters of spheres in a section from the distribution of apparent diameters. By applying the Wicksell transform equa-

Table 1. The morphometric parameters measured at different electron micrograph magnifications

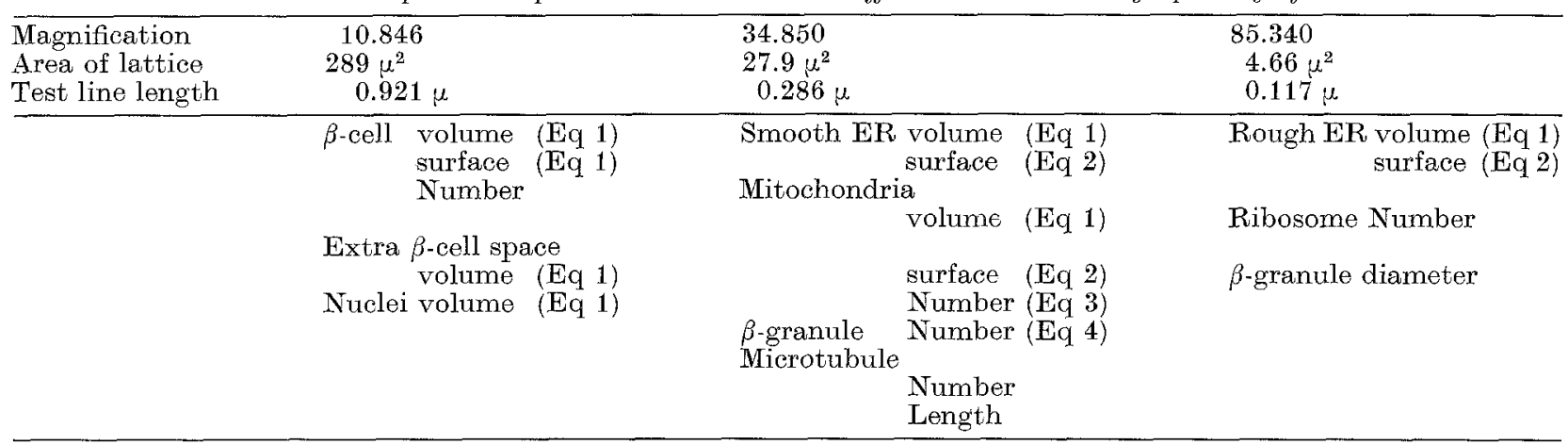

Table 2. Morphometric parameters for islet $\beta$-cells from mouse pancreas

\begin{tabular}{|c|c|c|c|c|c|c|}
\hline Component & Parameter & $\begin{array}{l}\text { Density per } \\
\mathrm{cm}^{3} \text { tissue }\end{array}$ & S.E.M. & Dimension & $\begin{array}{l}\text { Value per } \\
\beta \text {-cell }\end{array}$ & $\begin{array}{l}\% \text { Volume } \\
\text { per } \beta \text {-cell }\end{array}$ \\
\hline$\overline{\text { Extra } \beta \text {-cell space }}$ & Volume & 0.112 & 0.006 & $\mathrm{~cm}^{3} / \mathrm{cm}^{3}$ & & \multirow{3}{*}{$100 \%$} \\
\hline \multirow[t]{2}{*}{$\beta$-cell } & Volume & 0.887 & 0.046 & $\mathrm{~cm}^{3} / \mathrm{cm}^{3}$ & $1434 \mu^{3}$ & \\
\hline & Surface & 0.602 & 0.061 & $\mathrm{M}^{2} / \mathrm{cm}^{3}$ & $973 \mu^{2}$ & \\
\hline \multirow[t]{2}{*}{ Nuclei } & Volume & 0.104 & 0.017 & $\mathrm{~cm}^{3} / \mathrm{cm}^{3}$ & $168 \mu^{3}$ & \multirow[t]{2}{*}{11.7} \\
\hline & Number & $618 \times 10^{6}$ & $75.5 \times 10^{6}$ & $\mathrm{~cm}^{-3}$ & 1 & \\
\hline Cytoplasm & Volume & 0.783 & 0.031 & $\mathrm{~cm}^{3} / \mathrm{cm}^{3}$ & $1266 \mu^{3}$ & 88.2 \\
\hline Cytoplasmic ground substance & Volume & 0.471 & 0.021 & $\mathrm{~cm}^{3} / \mathrm{cm}^{3}$ & $764 u^{3}$ & 53.2 \\
\hline \multirow[t]{2}{*}{ Total endoplasmic reticulum } & Volume & 0.174 & 0.012 & $\mathrm{~cm}^{3} / \mathrm{cm}^{3}$ & $280 \mu^{3}$ & \multirow[t]{2}{*}{19.5} \\
\hline & Surface & 5.27 & 0.505 & $\mathrm{M}^{2} / \mathrm{cm}^{3}$ & $8517 \mu^{2}$ & \\
\hline \multirow{2}{*}{ Rough ER } & Volume & 0.118 & 0.012 & $\mathrm{~cm}^{3} / \mathrm{cm}^{3}$ & $191 \mu^{3}$ & \multirow{2}{*}{13.5} \\
\hline & Surface & 3.81 & 0.354 & $\mathrm{M}^{2} / \mathrm{cm}^{3}$ & $6158 \mu^{2}$ & \\
\hline Bound ribosomes & Number & $8.31 \times 10^{14}$ & $0.384 \times 10^{14}$ & $\mathrm{~cm}^{-3}$ & $1.34 \times 10^{6}$ & \multirow{3}{*}{6.2} \\
\hline \multirow[t]{2}{*}{ Smooth ER } & Volume & 0.055 & 0.012 & $\mathrm{~cm}^{3} / \mathrm{cm}^{3}$ & $89 \mu^{3}$ & \\
\hline & Surface & 1.45 & 0.656 & $\mathrm{M}^{2} / \mathrm{cm}^{3}$ & $2359 u^{2}$ & \\
\hline \multirow[t]{2}{*}{ Mitochondria } & Volume & 0.034 & 0.006 & $\mathrm{~cm}^{3} / \mathrm{cm}^{3}$ & $56 \mu^{3}$ & \multirow[t]{2}{*}{3.9} \\
\hline & Number & $616 \times 10^{9}$ & $113 \times 10^{9}$ & $\mathrm{~cm}^{-3}$ & 996 & \\
\hline Mitochondrial envelope & Surface & 0.482 & 0.085 & $\mathrm{M}^{2} / \mathrm{cm}^{3}$ & $779 \mu^{2}$ & \multirow{6}{*}{11.5} \\
\hline \multirow{2}{*}{$\beta$-granules } & Volume & 0.102 & 0.011 & $\mathrm{~cm}^{3} / \mathrm{cm}^{3}$ & $166 \mu^{3}$ & \\
\hline & Number & $0.808 \times 10^{13}$ & $0.093 \times 10^{13}$ & $\mathrm{~cm}^{-3}$ & 13060 & \\
\hline \multirow[t]{2}{*}{ Microtubules } & Number & $1.79 \times 10^{12}$ & $0.628 \times 10^{12}$ & $\mathrm{~cm}^{-3}$ & 2905 & \\
\hline & Length & $7.58 \times 10^{5}$ & $1.66 \times 10^{5}$ & $\mathrm{M} / \mathrm{cm}^{3}$ & $1226 \mu$ & \\
\hline$\beta$-granules attached & Number & $5.49 \times 10^{11}$ & $1.20 \times 10^{11}$ & $\mathrm{M}^{-1}$ & 887 & \\
\hline
\end{tabular}

Mitochondria occupy about $4 \%$ of $\beta$-cell volume, there being 996 mitochondria per cell calculated using equation 3 . The volume and surface area of a mitochondrion was calculated to be $0.0567 \mu^{3}$ and $0.782 \mu^{2}$ respectively. These values were derived from line and point counting methods and can be checked by direct measurement of the axial ratios of mitochondria. Mitochondrial profiles indicate that the organelles were cylindrical with a mean diameter of $0.301 \mu$ and an axial ratio of 2.367 .

Thus, the volume and surface area for an individual tions for a 20 class histogram the distribution of true diameters of $\beta$-granules was found (Fig. 2). The mean diameter was $0.289 \mu$. Using this value in equation 4 the number of $\beta$-granules in $1 \mathrm{~cm}^{3}$ of islet tissue was estimated to be $0.808 \times 10^{13}$, corresponding to 13060 $\beta$-granules per cell. The volume of a $\beta$-granule, assuming spherical shape, was $0.012 \mu^{3} ; \beta$-granules, therefore, occupy $11.5 \%$ of cell volume.

Only microtubule fragments with longitudinal profiles could bo identified, circular profiles could not be easily distinguished from other intracellular organelle 
fragments. Profiles with axial ratios less than 3 were not counted. The number of microtubules were counted in a micrograph area representing a volume of 2.099 $\mu^{3}$ and then related to the volume of cell cytoplasm. This value was multiplied by 1.8 to correct for the loss of profiles with axial ratios less than 3 . The number of microtubular fragments calculated per cell was 2905 with a mean fragment length of $0.422 \mu$, hence the total length of microtubules per cell was $1226 \mu$.

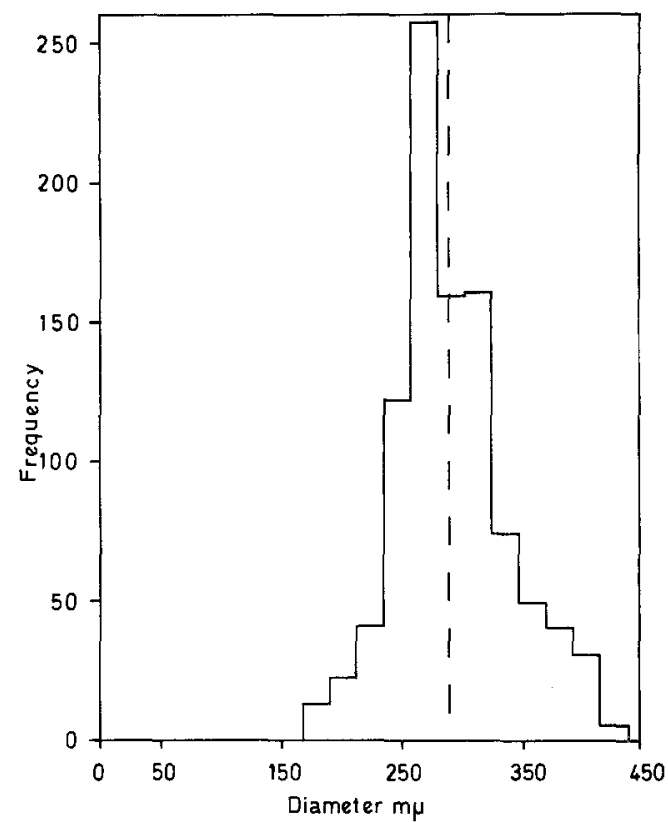

Fig. 2. Frequency distribution of the true diameters of $\beta$-granules. The true mean diameter is shown by the broken line. Total number of granule diameters measured was 1000

The number of $\beta$-granules attached to microtubule profiles was counted and estimated to be $\mathbf{8 8 7}$ per cell. Therefore, $6.8 \%$ of the $\beta$-granules in a cell were attached to microtubules. It can be calculated that the number of $\beta$-granules expected to be contained in a cylindrical volume element one granule diameter and $1226 \mu$ long, placed at random in the cell cytoplasm, is 833 granules, i.e. $6.4 \%$ of the total number of $\beta$-granules in a cell. The observed value of $6.8 \%$ is, therefore, extremely close to that expected solely for chance associations of $\beta$-granules with microtubules.

\section{Discussion}

The electron micrograph sections that have been analysed in this study have been taken from islet tissue fixed and embedded in epon. As with all studies of this nature it is quite possible that the histological treatment can produce volume changes in the tissue. Indeed, in his analysis of pancreatic tissue, Hellman (1959) has clearly demonstrated by light microscopy a tissue volume shrinkage during fixation and embed- ding. However, one fundamental problem remains: what part of the tissue shrinks, is the extracellular space altered or is cell volume changed? Even more difficult to assess is the extent to which the volumetric densities of the ultrastructural components are affected by the histological procedure: with the present techniques available no simple solution to this problem seems apparent. Therefore, having these important reservations in mind, values for the morphometric parameters of the ultrastructural components of $\beta$-cells have been calculated.

Stereological analysis is quite simply the applica. tion of statistical geometry to samples of sectioned material randomly taken from a population of sections. Systematic errors are likely to arise either from incorrect identification of structural profiles or from structural anisotropy in the sectioned material. From 250 electron micrographs of islet sections, no section showed any apparently preferred orientation of organelles. Since the samples were obtained in a random sectioning plane, it has been assumed in this study that pancreatic islet $\beta$-cells are structurally isotropic, so that equations $1-4$ outlined in the methods section can be applied to the morphometry of $\beta$-cells.

The most important systematic error in the methodology used here related to a loss of endoplasmic reticulum membranes and $\beta$-granules because tangential sections of these organelles could not be identified with certainity. It is also possible for $\beta$-granules to be sectioned without the profile containing electron dense material, in this case the profile would have been identified as smooth endoplasmic reticulum and not as a $\beta$-granule. However, in the measurement of $\beta$-granule diameter, the procedure adopted from the method of Wicksell does account for loss of small profiles caused by finite section thickness. Small profiles are usually missed to an increasing degree the smaller they are, mainly because of lack of contrast in polar sections. Very often no profiles were recorded in the smallest size classes. Such profiles include many of the sections passing near the pole of the granules from any size class, together with a few equatorial profiles; the error made in estimating the distribution of true diameters by Wicksell's method is small since only equatorial profiles enter into the mathematical transformations of apparent diameters into true diameters. The result is less than that expected from the contribution of the larger granules; nevertheless the calculated distribution of true granule diameters is unaffected. Therefore the size and number of $\beta$-granules probably do not require correction. With the exceptions of the parameters for smooth endoplasmic reticulum, mitochondria and microtubules the standard errors of the means were less than $16 \%$.

Morphometric studies similar to the one described here have been performed by Weibel, Staubli, Gnagi and Hess (1969) for hepatocytes and can be used for comparison with the data obtained for $\beta$-cells. $\beta$-cells 
occupied about $88 \%$ of islet volume with a mean cell volume of $1434 \mu^{3}$ and polyhedral in shape; $\beta$-cells were approximately one quarter of the size of hepatocytes. Although the nuclear volume in $\beta$-cells was smaller than for the hepatocytes, the relative volume of the nucleus compared with cell size was greater in $\beta$-cells. Both cell types have the same fractional volume of cytoplasmic ground substance $53 \%$ of cell volume. Hellman (1959) has measured, using light microscopy, the size of the nucleus and volume of $\beta$-cells from rat pancreatic islets. In the 100 day old rat pancreas both the nuclear volume and $\beta$-cell volume were much smaller, $111 \mu^{3}$ and $875 \mu^{3}$ respectively, compared with values of $168 \mu^{3}$ and $1434 \mu^{3}$ found for mouse islet $\beta$-cells. The volume fraction of $\beta$-cells in rat islets was also smaller, about $80 \%$, compared with $88 \%$ for mouse islets.

The volumetric ratio of smooth and rough endoplasmic reticulum was similar, 0.62 and 0.46 , for hepatocytes and islet $\beta$-cells respectively. The relative volume of total endoplasmic reticulum was $19.5 \%$ for $\beta$-cells and $15.2 \%$ for hepatocytes. There were 218 ribosomes bound to $1 \mu^{2}$ of rough endoplasmic reticulum in $\beta$-cells, compared with 334 for hepatocytes. A striking difference was observed however, between the mitochondrial volume in $\beta$-cells and hepatocytes; mitochondria from $\beta$-cells have a volume of $0.056 \mu^{3}$, smaller by a factor of 10 than hepatocyte mitochondria.

$\beta$-Granules were found to occupy a considerable fraction of total cell volume, $11.5 \%$, as much in fact as the nucleus; the mean number of granules being 13060 per cell. The granules were distributed generally throughout the cytoplasm and were not apparently concentrated in any region. Ekholm, Ericson and Lundquist (1971) have estimated that $\beta$-granules occupy about $30 \%$ of the volume of mouse pancreatic $\beta$-cells, a value which is approximately three times the volume fraction found in the present work: however strict comparison between the results is not possible since the standard errors were not quoted. Some $\beta$-granules were seen to be attached to microtubules although the number adjacent to a microtubule was not higher than the value expected from chance positioning. The functional significance of microtubules in $\beta$-cells is unknown but it has been postulated by Lacy and Howell (1970) that $\beta$-granules are positioned alongside the microtubules prior to release by exocytosis. However, the results presented here would suggest that there is little or no preferential storage of $\beta$-granules along the microtubules.

The morphometric parameters determined in this study are presented for the ultrastructural components of the $\beta$-cell in the "resting state". It must be emphasized that the islet tissue had been incubated for $1 \mathrm{~h}$ in Krebs-Henseleit solution before fixation and that this procedure may have altered the morphology from in vivo conditions. To what extent such changes could have been produced is unknown, nevertheless any differences could be determined simply by comparing the morphometry of freshly fixed tissue with incubated tissue. However, it should be possible to use this stereological information as a firm basis for comparison with known biochemical and biophysical properties of the $\beta$-cell in the stimulated and unstimulated state and so to construct a quantitative model for insulin secretion.

Acknowledgements. I thank Dr. E.K. Matthews for encouragement during this work and Mr. D. Chapman for his valuable technical assistance.

\section{References}

Dean, P.M., Matthews, E.K.: Glucose-induced electrical activity in pancreatic islet cells. J. Physiol. 210, 255264 (1970a).

Dean, P.M., Matthews, E.K.: Electrical activity in pancreatic islet cells : effect of ions. J. Physiol. 210, 265$275(1970 \mathrm{~b})$

De Hoff, R.T., Rhines, F.N.: Determination of the number of particles per unit volume from measurements made on random plane sections: the general cylinder and the ellipsoid. Trans. Amer. Inst. Mining. Met. Petrol. Engrs. 221, 975-982 (1961).

Ekholm, R., Ericson, L.E., Lundquist, I. : Monoamines in the pancreatic islets of the mouse. Subcellular localization of 5 hydroxytryptamine by electron microscopic autoradiography. Diabetologia 7, 339-348 (1971).

Elias, H.: Stereology. Proc. 2nd Int. Congr. for Stereology. Chicago 1967. Berlin-Heidelberg-New York: Springer-Verlag 1967.

Elias, H., Hennig, A., Schwartz, D.E.: Stereology: applications to biomedical research. Physiol. Rev. 51, $158-200(1971)$.

Haug, H.: Probleme und Methoden der Strukturzählung im Schnittpräparat. In: Quantitative methods in morphology, p. 58. Weibel, E.R., Elias, H., editors. Berlin-Heidelberg-New York: Springer-Verlag 1967.

Hellman, B.: The total volume of the pancreatic islet tissue at different ages of the rat. Acta path. microbiol. scand. 47, 35-50 (1959).

Hellman, B. : Methodological approaches to studies on the pancreatic islets. Diabetologia 6, 110-120 (1970).

Weibel, E.R.: Stereological principles for morphometry in electron microscopic cytology. Int. Rev. Cytol. 26, $235-302(1969)$.

Weibel, E.R., Kistler, G.S., Scherle, W.F.: Practical stereological methods for morphometric cytology. J. Cell. Biol. 30, 23-38 (1966).

Weibel, E.R., Staubli, W., Gnägi, H.R., Hess, F.A. Correlated morphometric and biochemical studies on the liver cell. 1. Morphometric Model, stereological methods, and normal morphometric data for rat liver. J. Cell Biol. 42, 68-91 (1969).

Wicksell, S.D.: The corpuscle problem. A mathematical study of a biometric problem. Biometrika 17, 84-99 (1925).

Lacy, P.E., Howell, S.L.: The mechanism of emiocytic insulin release. In: Structure and metabolism of pancreatic islets, p. 171-180. Ed. Falkner, S., Hellman, B., Täljedal, J.B. Oxford: Pergamon Press 1970.

\author{
Dr. P. M. Dean \\ Dept. of Pharmacology \\ University of Cambridge \\ Medical School \\ Hills Road \\ Cambridge CB 22 QD \\ England
}

